\title{
A NEW AND ALTERNATIVE LEADERSHIP MODEL TO ANALYZE THE ROLE OF LEADERS IN FOREIGN POLICY
}

\section{ŞUAY NILHAN AÇIKALIN}

suaynilhan@gmail.com

Assistant Professor, Department of International Relations, Ankara Haci Bayram Veli University (Turkey). Her current research centers leadership of Angela Merkel and Recep Tayyip Erdoğan vis a vis Turkish-German relations and her research interests are Turkey- EU relations, integration of

Syrian refugees in Turkey, youth work. Also, she has been working on application of chaos and complexity theory in international relations, and gastrodiplomacy and fashion diplomacy

\begin{abstract}
The role of leaders in foreign policy analysis has an extensive literature and comprises subfields. Operational code and leadership trait analysis are prominent qualitative methods used in the field. However, the changing nature of international relations encouraged a rethink of the role of leadership in foreign policy and the analysis approach. In this respect, this article aims to introduce a new alternative leadership model, which is called the SNA Leadership Model, developed with four dimensions of; i) contextual background of the country, ii) personal background of the leader, iii) approaches and behaviors, and iv) reflections of background in making foreign policy. The model is developed as a new perspective about the role of leaders in foreign policy through an eclectic and holistic approach.
\end{abstract}

\section{Keywords}

Political leadership, model, foreign policy, approaches, behavior

\section{How to cite this article}

Açikalin, Şuay Nilhan (2021). A New and Alternative Leadership Model to Analyze the Role of Leaders in Foreign Policy. In Janus.net, e-journal of international relations. Vol12, No. 2, November 2021-April 2022. Consulted [online] on the date of the last visit, https://doi.org/10.26619/1647-7251.12.2.1

Article received on March 17, 2021 and accepted for publication on September 7, 2021

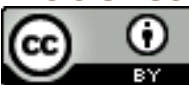




\title{
A NEW AND ALTERNATIVE LEADERSHIP MODEL TO ANALYZE THE ROLE OF LEADERS IN FOREIGN POLICY
}

\author{
ŞUAY NILHAN AÇIKALIN
}

\section{Introduction ${ }^{1}$}

Making foreign policy is a dynamic and complex process, which comprises various actors which make the process difficult to analyze. Among these various actors, political leaders have undeniable effects in making foreign policy; however, scholars were late in focusing on understanding the role of leaders rather than structural factors (Horowitz and Fuhrmann, 2018).

From the historical perspective, the Cold War was a fruitful time for studying leaders with psychology and organization perspectives in order to analyze making foreign policy (Byman and Pollack, 2001). The origins of studies about the role of leaders in foreign policy analysis are two works; 'Decision-Making as an Approach to the Study of International Politics' by Richard C. Snyder, H. W. Bruck, and Burton Sapin (1954) and 'Man-Milieu Relationship Hypotheses in the Context of International Politics' by Harold and Margaret Sprout (1965). The work by Richard Snyder, H.W. Bruck and Burton Sapin called Decision Making claimed that leaders who act on behalf of the state take action and used this as an approach to study international relations (1962). One of the main assumptions of the article focused on leaders as a decision unit who pursued a specific objective $(1954 ; 2002)$. As inevitably reflected in the literature, through the Cold War American policymakers and scholars gained interest in the psychological traits of foreign leaders to predict future motives of these leaders (Renshon and Renshon, 2008). Since then, the literature analyzing the role of leaders in making foreign policy has been growing. Two distinctive approaches have been used widely as qualitative methods, operational code and leadership trait qualitative methods, and each involve their own limitations. The personal background and characteristics of the country, especially, were ignored in these approaches.

Modeling is a unique form for developing and constructing of new ideas. Constructing a model in social science is a popular tool to both visualize and analyze phenomena, which also allows flexibility for scholars.

In light of this, the article aims to introduce a new approach to analyzing the role of leadership in making foreign policy called the SNA Leadership Model, named based on the initial letters of the author's name.

This article was prepared from the author's PhD thesis entitled "Leadership and Foreign Policy: Recep Tayyip Erdoğan and Angela Merkel" 


\section{Overview of Existing Approaches to Analyzing Leaders in Foreign Policy Analysis}

As mentioned in the introduction, the literature about analyzing leaders' roles in making foreign policy is dominated by two approaches of operational code and leadership trait analysis (Erhan and Akdemir, 2018). Firstly, operational code analysis was originally developed by Nathan Leites to analyze the strategies of Soviet Politburo members in 1950. Alexander George developed the method of 'operational code of analysis' in his work called 'The Operational Code: A Neglected Approach to the Study of Political Leaders and Decision-Making' (1969). The method he developed involves classifying and comparing individual leaders depending on certain political beliefs which are assumed to influence the leader's perception of the world and how they make decisions in foreign policy in two dimensions of philosophical and instrumental (George, 1969). In order to identify this process, Alexander developed sets of questions for both dimensions. In recent years, this method was developed as a computer-coding system by different scholars. Examples include Marfleet and Miller's "Failure after 1441: Bush and Chirac in the UN Security Council" (2005), Malici and Malici wrote "The Operational Codes of Fidel Castro and Kim Il Sung: The Last Cold Warriors" (2005) and Renshon's article called "Stability and change in belief systems: The operational code of George Bush" (2008).

The second prominent method used for analyzing the role of political leadership in foreign policy is leadership trait analysis (LTA). This framework was developed by Margaret Hermann and contributed the personal characteristics of leaders making foreign policy to the literature (Hermann, 1980, 1983, 1984, 1987, 2003). In this approach, personality is defined as a combination of seven traits: belief in their ability to control events, conceptual complexity, need for power, distrust of others, in-group bias, self-confidence, and task orientation (2003). According to Hermann (2003), the selected seven traits trigger the emergence of specific behaviors in leaders. In other words, leaders who have high belief in their ability to control events and need for power, for example, are expected to challenge constraints; however, leaders with low belief in the need for power and/or who do not believe they can control events are expected to respect constraints. In addition to this, conceptual complexity and self-confidence are linked to characteristic of openness to information. Thus, Hermann suggested that leaders with high scores for traits and leaders who have high complexity and low self-confidence are expected to be open to information; however, leaders with low scores for both traits and leaders with high self-confidence and low complexity are expected to be closed to information. Through the years, LTA became one of the preferred tools to analyze the role of leaders in making foreign policy.

The two dominate approaches given in detail focus on psychological assessment of leaders and how it affects foreign policy mostly from a qualitative method perspective. On the other hand, Post contributed a quantitative method for analysis of psychological assessment for political leaders in foreign policy with the psychobiography approach (1979). Within the next decades, Post created a research team composed of psychiatrists, internists, psychologists, anthropologists, historians, and intelligence analysts to develop classified leadership profiles of various world leaders for the intelligence community and senior U.S. policy makers (Dekleva, 2018). 
However, these approaches involved their own limitations. Levy underlined the two main problems of generalizing the high stakes and high stress world of elite in the decisionmaking process (2013). Furthermore, psychological assessment models do not provide holistic explanations for making foreign policy and lack explanations about the role of domestic and international conditions, as well leaders' personal background. In other words, each leader and their making of foreign policy can be deemed sui generis due to domestic constraints and interpretation of their background.

\section{Building a Model in Social Sciences}

The literature and main approaches about political leaders and foreign policy are given in the previous sections. In this respect, a new approach is introduced with a model which can be used by researchers who do not just aim to compare and contrast leaders' beliefs and motivations, as well as their psychological traits and their emotions only. Also, notions and terms from various disciplines are consciously used in order to shed light on the interdisciplinary nature of leadership. Because of this, the idea of developing a new leadership model comprising these notions can be considered interdisciplinary.

Although constructing models is rare in the social sciences, the aim of modelling is to produce more customized, sophisticated, and artistic models (Little, 1993). Modeling plays a vital role in scientists' motivation to understand the world and phenomena (Toon, 2016). Hutten (1954) and Braithwaite (1953) stressed the importance of models in science within different aspects as follows:

- Tools for thinking and theory development

- To provide descriptive vocabulary

- Models are naturally incomplete and "not literal"-that is, they leave out things and are potentially misleading.

In addition to this, models useful in different fields of science mostly focus on the general agreement among philosophers of science because models provide knowledge that represents some real-world 'target systems' (Frigg, 2002; Giere, 2004; Mäki, 2009; Ramadas, 2009; Coll \& Lajium, 2011). While a theory attempts to explain a phenomenon, a model tries to represent the phenomenon (Bhattacherjee,2012). Various understandings and explanations of modeling should be emphasized here. There are different meanings involved in the notion of modeling including statistical models, decision analysis, procedures and algorithms and social science theories (Checkland, 1981; Little, 1993).

In order to clarify this misunderstanding, here I employ modeling as a representation of a way of thinking; models are always interpretive and not simply driven by the phenomena (Bailer-Jones 2009). Models are products of, and tools for, particular kinds of thinking (Morrison \& Morgan, 2000; Winsberg, 2001). Through modeling, complex phenomenon are simplified (Heyck, 2015). This simplifying can be done in different ways such as scaling down or up, reducing the number of variables or components, idealizing or abstracting from concrete situations, making something new and strange more familiar through analogy or representation in an easy form, visualization and more (Coll \& Lajium, 
2011; Heyck, 2015). In light of this, model building can be considered both an art and also a craft comprising a mixture of elements from inside and outside the original field of investigation (Moris \& Morgan, 2000).

There are different analytical tools and models that can be used for foreign policy analysis, especially with the intensive use of information technologies, which have three main common elements with different degrees of depth of analysis. These elements are: (1) individual actors, who do what they like through collation and influence; (2) the cognitive process, either related to agenda setting or one of the stages of the policy process; and (3) political environment and the conditions surrounding the policy maker including political, social or economic factors (Hamza \& Mellouli, 2018).

\section{New Alternative Leadership Analysis Model}

The new alternative leadership model was developed as a tool to understand behavior patterns of leaders in making foreign policy in a limited manner. This model was named SNA, based on the initials of the authors' names. There are different elements which determine the making of foreign policy at leadership level such as institutional structure of the state, history, personality and psychological elements of the leader, etc. This model only considers the background of the country and personal background of the leader and selected approaches and behaviors, which are limitations of this model. In other words, this model only focuses on approaches and behavior of leaders that produce specific foreign policy patterns. It should be noted that ideas within these four dimensions are not only limited to the field of international relations, but also come from various disciplines.

In the SNA Leadership model, the first dimension is the contextual background of the country, which includes mode of governance, political system and political characteristics of the country. In addition to this, the model features the historical perspective of the country to draw a picture of conditions when the selected leader first came to power. The second dimension is the biography of the leader, which provides insights from their childhood, youth and early political life. This dimension is inspired from the integrated political personality profile of Jerold Post as follows; 1 ) psychobiographic discussion, 2) personality, 3) worldview, 4) leadership style, and 5) outlook (2014: 329). The third dimension is approaches and behavior of the leader that combines ideas with a multidisciplinary perspective. The fourth and last dimension includes six patterns for foreign policy of leaders developed based on the third dimension of the SNA Leadership Model.

The visualization of the SNA Leadership Model is shown in Figure 2. In Figure 2; each circle represents each dimension of the SNA Leadership Model, which are named D1, D2, D3 and D4. Also, light points on each circle indicate subtitles in the dimensions. Eight light points represent a total of four approaches and four behaviors in the third dimension. Lastly, six light points symbolize six patterns in the fourth dimension of the SNA Leadership Model. 
Figure 1: Visualization of the SNA Leadership Model developed by the author

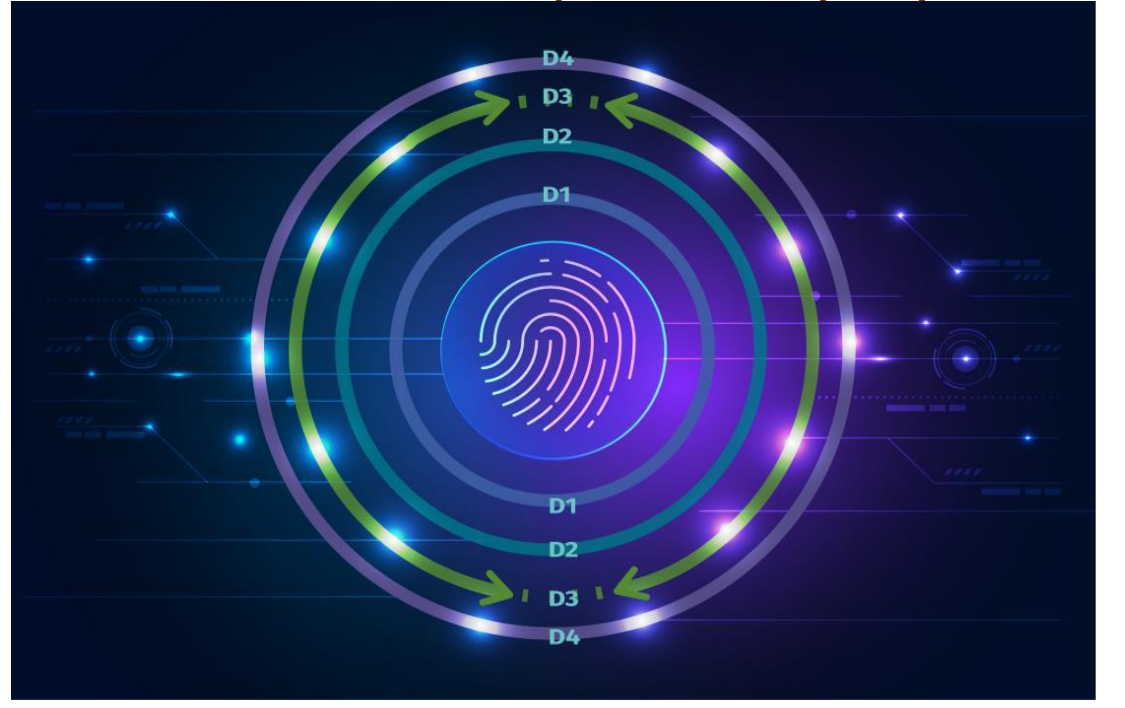

\section{D1: Contextual Background of the Country in Which the Leader was Born and} Raised

The socio-political and cultural context of the country are undeniable factors and leadership is given meaning by the contextual background of the country, while leaders also add new meaning to the contextual background of their country. The socio-political and cultural context creates sociological, political and psychological conditions for formation of leadership. These elements are fundamental determinants of the perceptions and judgments that cause a person to be adopted and accepted as a leader in a society. The socio-political and cultural context of the country gives meaning to leadership and also determines the type of leadership. This is an undeniable reality for influencing and unifying people to gain power and action while pursuing clear goals and creating a common future, as well as changing the socio-political and cultural context of the country. Thus, the leader is someone who can play the role of both evaluating and knowing the socio-political and cultural context and its resulting elements, and is also able to reshape and recreate socio-political and cultural visions for the future. Thus, the leader is an element of the socio-political and cultural context that adds new meanings to the socio-political and cultural context of their country.

\section{2. Background of the Leader}

The early years and experiences of leaders can be used as a guide to understand their motivations and policy-making process (Breuning, 2007). In this respect, the SNA Leadership Model analyzes the background of the leader based on two sub-categories of personal background and political life from past to present. In the first sub-category, the leader's family, socialization processes, student years, success and failures and critical events in life are given. In addition to this, their physical appearance, life and working style are included to evaluate esthetic sensitivity as well. The second sub-category 
includes development of leader's political career and their politics in different political positions.

\section{3. Approaches and Behaviors in Political Leadership}

The third dimension can be deemed one of the most original sections of the SNA Leadership Model comprising the approaches and the behaviors of political leaders. "Approach may be defined as the basic philosophy or belief concerning the subject matter being considered" (Höfler, 2005). Approach is the set of assumptions or perspectives held by individuals related to their field. In this respect, the SNA Leadership Model is a holistic multidimensional model providing new perspectives for how people understand, perceive and analyze the notion of leadership. Chowdury defines the notion of holistic as follows; "Being holistic means developing systems 'state of mind' which enables the practitioner to chart interrelationships, recognize emergence and work with and challenge different mental models reflecting alternative boundary judgments" (2019). Constructs are described as multidimensional when their indicators are themselves latent constructs (Edwards, 2001:145). So, a multidimensional construct represents a theoretically meaningful, overall abstraction that relates these various latent constructs to each other (Law et al., 1998). Political leaders who adopt this approach are naturally expected to deal with facts in a holistic multidimensional way. In this sense, leaders will try to both perceive the big picture and not ignore the details at the same time, which leads to the multidimensional and dynamic nature of the holistic approach that leaders adopt in their behavior. In this respect, the multidimensional and holistic perspective plays a key role in determining the four approaches and behaviors selected in the model.

\section{Approaches}

Awareness of the chaotic nature of the system: Social systems are naturally complex systems that include various actors with endless interactions in an international system (Geyer and Rihani, 2010). In these systems, leaders will be aware that they have to make decisions within a complex system where their actions can have unanticipated effects, to approach their goals indirectly through multiple paths in order to reduce the risk of failure, and to adopt careful and cautious policies while expecting dangerous nonlinear consequences (Jervis, 1997). The expected approach from a leader includes awareness of the structure of the system, exploration of the basic elements that affect the system and the relationship of these factors affecting the system periodically and taking into account the power of network in decision-making. These realities emphasize the importance of having a multidimensional leadership profile beyond the usual leadership traits (Erçetin et al., 2013; Erçetin et al., 2014).

Thinking in kaleidoscopic and catalytic ways is important for leaders. Catalytic and kaleidoscopic thinking means a high level of awareness and sensitivity regarding the fluidity and intensity of continuous change within the international system. This thought system makes leaders sensitive to events where the phenomenon can always have different perspectives which enable the leader to obtain higher levels of commitment and performance from people. Furthermore, Petrini considered a 
metaphor for kaleidoscope creativity; "reorganizing different parts that create a new reality" (1991:27). Similarly, Harris (2009: 78) emphasized that catalytic and kaleidoscopic thinking is an emergent event that can trigger entirely new possibilities due to the change in perspective. Indeed, Harris defined catalytic and kaleidoscopic thinking as planning for the future which is 'not there yet'. In today's complex and uncertain world, leadership and characteristics of leadership change rapidly and intensely according to time and situation (Bennet, 2016).

Being Glocal: The word glocal comes from the Japanese word 'dochakaku' (Tulloch, 1992). In recent years, Roland Robertson defined the notion of glocal and glocalization as the dual character of the globalization process; being 'globalization' and 'localization' simultaneously (1992). In the global context, leaders demonstrate high level of awareness and sensitivity about what is happening. Specifically, developing policies vis-a-vis developments in their own countries. At the same time, the power and sphere of leaders has been increased by the globalization of local social, cultural, economic and political values. As Erçetin and the others suggest, glocal leadership requires a glocal strategy where all stakeholders should think globally and act locally (2017: 76). Likewise, leaders require unique glocal strategy to promote their own local values on a global scale.

Having unique values for humanity: Allport and Vernon defined values as basic convictions or philosophy of an individual about what is and is not important in life (1931). Their definition of value also represents desirable goals in people's life. In other words, values are a vital element that is determinant of personal attitudes and behavior (Rokeach, 1973). This led to the question; are the values that they adopt what makes leaders unique compared to others? Leaders with values define a set of criteria. These criteria are generally shared in society within different aspects, such as events, facts, objects and people. The values presented by the leader are products of the historical and cultural background of the country, and also the current context and the future. The leader's values also reflect goals to be achieved in society through vision. Leaders who perceive their country as a global power or who aim to be a world leader themselves, try to create unique values for humanity that can be universally accepted. Stückelberger suggested that time and space contexts are influential in formation of values, including geographical conditions, ethnic identities, religious convictions, gender diversity, generational transformations, technological innovations and forms of organization in communities which can be collectively called contextual values (2016). These contextual differences may inevitably conflict with each other. Therefore, it is tough to set unique values for humanity and convert them into values which will be adopted by large masses of people both in their own country and externally where human beings are naturally part of an interconnected world (Raines, 2013). Lastly, it should be noted that when value acceptance is high around the world, the power and influence of the leader also increases within the international context.

\section{Behaviors}

Behavior is defined as a set of actions within a web of relationships where dynamic interaction plays key role (1991). Also, behavior is observable activity of humans that is 
sourced from the accumulation of responses to internal and external stimuli (Flexner et al., 1987). Thus, 'the contextual background of the leader's country' and 'the background of the leader' play influential roles in this new model.

- Production of entangled solutions is defined as an important feature of the universe as revealed by Alain Aspect and his group in 1982. Aspect proved experimentally that the universe has invisible bonds and that objects are connected to each other. If micro particles are able to make immediate contact with each other, the reason for this is not that they send signals to each other, but rather they act as a single unit which means separation is an illusion. 'Entanglement', in other words, signifies a relationship so intensely and densely connected that it shows the unrealistic existence of separate phenomena. These phenomena should be considered to instead form a wider unified system, or even a kind of 'nondualistic whole' (Elbe and BucklandMerret, 2019). Thus, it reveals chronic problems in producing concurrent solutions for both prospective problems and solutions that will affect the whole international system and its actors. It is very important for a political leader to produce policies with this awareness. The policies that the leader produces with human, moral and legal values will ensure that, even if not immediately, they will be successful because of the deeper level of reality.

- Determinants of uncertainties: Determinants of uncertainties means to be flexible and ready to make a timely transformation based on these uncertainties. It is one of the most important behaviors that political leaders must have in order to capture temporality and to react to situations in a timely manner (Erçetin, 2016). This is particularly important during times of crisis when unpredictability is at its height and survival within national and international platforms is the top priority and critical for leaders. As Petzinger mentioned, the emergence of 'dynamic tension' during the crisis period involves multidimensional potential and advantages for all actors (1999). That's why, being timely and flexible are important characteristics to be determinant of uncertainties. Kesselring claims that modern living involves constant change, motion and transit (2008). In these social systems, flexibility is a liquidity where changing and transformation is normal (Bauman \& Haugaard, 2008). From this perspective, leaders are expected to be flexible in order to make well-timed decisions. Otherwise, their decisions will create irreversible consequences for their countries and the international system. In this sense, it can be said that leaders gain influence and power in the international system by shaping the trends and interactions that occur, rather than controlling the behavior of the international system. Therefore, leaders should be determinant of uncertainties as normal through various scenarios and designs, along with the priority and interests of their country. Leaders should set new policies and agendas based on new circumstances with regard to uncertainties.

- Simplexity: The notion was borrowed from Kluger's (2008) book called Simplexity: Why Simple Things Become Complex (and How Complex Things Can Be Made Simple). Kluger defined simplexity as "a groundbreaking new concept that reveals the hidden ways the world really works. From the micro to the macro, simplexity is a startling reassessment of the building blocks of life and how they affect us all." Gribbin defined simplexity as an idea located between complexity and simplicity. Furthermore, Berthoz 
(2012) explained simplexity as more than mixing of complexity and simplicity as follows:

Given the complexity of natural processes, the developing and growing brain must find solutions based on simplifying principles. These solutions make it possible to process complex situations very rapidly, elegantly, and efficiently, taking past experience into account and anticipating the future.

When it comes to simplexity in the leadership context, it can be defined as a set of behaviors that ensure analysis by synchronizing events on national, regional and global scales, while including holistic and multidimensional solutions. Just as Berthoz defined simplexity, political leaders are expected to be dynamic, creative and unexpected in expressing their unique leadership styles, vision and intelligence as opposed to the conventional approaches of leaders. Political leaders should be able to think complexly, but also have the ability to turn complexity into an asset. It needs to be simple, clear and goal-oriented to encompass complexity. In addition to this, simplexity can be found in their rhetoric as well. Lassiter claims that usage of language is a complex process, which would be matured by the simplexity process but should be simple yet rich in terms of meanings and content in order to energize the masses (2019). In other words, leaders should use simple language to explain complex phenomena to people.

- Create the attraction field is knowing that the influence and power of leadership depends on interacting with others and the nature of these interactions. Multidimensional interactions always bring serious risks for political leaders due to the unpredictability of interactions that may develop and the kind of effects that will occur. Political leaders are aware of this reality and do not fear intense interactions. Even the political leaders who are luck makers that create an attraction field that expands with each interaction. In other words, they increase their social networks through interactions, making people feel their presence and duty at any time throughout instant interactions. They wisely evaluate their interactions in order to increase the power of their political capital which consists of people, experiences, and phenomena. They can use the latest technology effectively for this purpose.

\section{4: Reflections of Backgrounds on Foreign Policy Making}

The third dimension of the SNA Leadership Model comprises approaches and behaviors that are shaped by the contextual background of leader's country and personal background. The fourth dimension of the SNA Leadership Model is reflections of the previous three dimensions on making foreign policy. Six foreign policy reflections were chosen as dynamic ideas which are products of the multidisciplinary leadership and international relations literature.

- Negotiation: Negotiation is one of the basic functions of diplomacy. Definitions of negotiation have varied through the years, but it commonly refers to a formalized process relying on verbal communication including a sub-class of bargaining aiming to reach an agreement between actors (Jönsson, 2002). Karns and others underlined the relationship between diplomacy and negotiations as follows; "diplomacy is a tool in international governance, while negotiation is an instrument of diplomacy" (2010: 3- 
4). As expected, leaders are expected to be an influential actor in negotiations, while negotiation as a vital component of leadership (Rubin, 2002; Zohar, 2015). Different behaviors make leaders great negotiators. Changing international environments have created more complex environments, which also reshaped the negotiation ability of leaders as well how leaders should determine new sets of strategies. Firstly, flexibility, leaders should adopt to different scenarios and possibilities to reach an agreement. Secondly, creativity which is also related to the strategy of flexibility that focuses on producing different scenarios. Thirdly, leaders should strengthen their personal relationships with other leaders to learn the social cues of the other negotiator. Fourth, leaders should be patient and not to give up negotiations and leaders should be tenacious in negotiation which is a process where persistence is important (Rubin, 2002; Mastenbroek, 2002).

- Connectivity: As the international system is highly chaotic, interdependency is the new normal which multiplied with the increasing numbers of actors. In other words, the boundaries between global and local become invisible (Tomé \& Açıkalın, 2018). The nested and more connected structure of the international system nudges leaders to reconsider how they perceive the international system. In this respect, Gelb defined connectivity as "the art of connection - creating and maintaining genuine rapport with others - is the key to building relationships, resolving conflict, and making creative possibilities come true" (2017: 26). In addition to this, Olson \& Singer discussed how connectivity is related with the leadership phenomenon as follows; "it is one of the three core leadership actions, along with contribution and collaboration, that fit with our complex and highly dynamic world" (2004: 45-48). Thus, leaders must anatomize the dynamics of regional and global events through the notion of connectivity, which can be realized on three levels of transactional, relational and social. Inevitable connectivity between different actors who foster interdependency between phenomena should be understood by leaders. In other words, even micro events between two actors can affect the international system. That's why leaders are able to use connectivity for power in foreign policy decisions in order to produce long-term policies.

- Personal diplomacy: Political leaders became more visible and central actors in making foreign policy in the last decade (Nuswantoro, 2010; Hinnebusch, 2018). In this international environment, the notion of "personal diplomacy" brings more meaning to policy making. Personal diplomacy can be defined as diplomatic efforts "when a particular national leader tries to sort out an international problem on the basis of their own personal relations with, and understanding of, other national leaders" (Robertson, 2002:147). There is no doubt; political leaders live in a social environment that is composed of other political leaders from different countries (Dumbrell, 2013). In this respect, personal interactions between political leaders should be taken account in international relations under certain structural, bureaucratic and psychological conditions (Ülgül, 2019). Thus, leaders' personal connections and communications with other leaders play an important role in making foreign policy. As mentioned, the connections and intensity between leaders in the international system are vital and can be intensified through face-to-face meetings and phone calls (Hall \& Yarhi-Milo, 2012). This can be considered to be an important 
driving force for the sphere of power, in terms of the international system and domestic politics in the leader's country.

- Entrepreneurship: According to Schumpeter, an entrepreneur is a person who is willing and able to convert a new idea or invention into a successful innovation (1942). It is considered to be an emergent characteristic for political leaders. As touched upon, the international system has given a more multidimensional role to individual actors, especially to leaders. There is increasing interest in political entrepreneurs, individuals who change the direction and flow of international politics (Klein et al., 2010). Thus, entrepreneur leaders are expected to seek innovative policies in the international system. In light of this, entrepreneurship is considered to be an indispensable characteristic of leaders. There are different entrepreneurial qualities, which are having a vision, being extravert, focused and decisive, opportunistic, agreeableness, persistent, having a kaleidoscopic perspective and confidence (Harper, 2006; Obschonka \& Fisch, 2018). Entrepreneur leaders who have these qualities should lead the process of affranchising the capabilities of societies and enabling them to identify and take ownership of ideas and pursue them by making something extraordinary with a common vision (Praszkier \& Nowak, 2011). In a changing world, leaders should have a strategy that includes entrepreneurial components that must embody some ideas or insights into new combinations of resources for dealing with both risks and opportunities at the same time (Schneider \& Teske, 1992).

- Solution seeking: Crises are a natural part of the international system. In the $21^{\text {st }}$ century, international crises have become multifaceted and interconnected (Ahmed, 2011; Avenell \& Dunn, 2016). Due to the nature of crises, they imply greater influence than expected, as leaders are at the heart of crisis diplomacy as decision makers. Bjola underlined that entropy sources in international crises demand strong leadership (2015). From this perspective, leaders first should define and analyze the crisis from different aspects, then create a feasible environment by creating teams to focus on solutions. In other words, leaders must come to the table with solution seeking resolutions which aim to solve common problems from the perspective of the larger picture and looking for long-term solutions in the best interest of all parties (Farrell, 2013). Leaders can be only solution seekers through a deep and multidimensional approach with different set of solutions. In other words, solution seeker leaders have both a solution seeking approach and a solution-focused mindset.

- Peace orientation: As mentioned in the solution seeking part, crises are a natural part of the international system. As well as crises, peace is also an idea that was identified in international relations from different angles. However, the SNA Leadership Model uses Galtung's positive and negative peace definitions (1996). Positive peace is that which is built upon positive relationships and interactions of human society. Establishing structural conditions that facilitate an environment built on positive interactions and engagements between actors is vital for peace. Negative peace, on the other hand, focuses on the reduction of violence, or efforts to solve current problems of conflict and discord (Galtung, 1996). Peace is not an exception that should be redefined in 21st century through enlarging and deepening vis-à-vis new security threats (Beyer 2018). Based on Galtung's definition, leaders are important in two ways, in both providing an environment, and being agenda setters. Mainly, leaders should provide both national and international environments with international 
organizations and other nations to ensure sustainable peace. Also, leaders can be agenda setters, which includes solutions to new types of security challenges such as immigration, hybrid wars, radicalization, environmental degradation and digital security as top priorities in the $21^{\text {st }}$ century (Bachmann, 2012). Consequently, leaders should be peace-oriented in their policy making for both foreign policy and domestic politics.

\section{Conclusion}

The SNA Leadership Model presents the background of the country, personal background, approaches and behaviors of leaders and their reflections in the leaders making of foreign policy. Though this model has similar elements to previous works about leadership in foreign policy, it introduces a new structure with four main dimensions of the contextual background of the country in which the leader was born, the background of the leader, the approaches and behaviors of the leader and reflections of leader's background in making foreign policy. Creation of the model was the product of long-term efforts to bring a new and fresh perspective to the literature. Compared to current approaches to analyze the role of leadership in making foreign policy, the SNA Leadership includes domestic and personal elements with multidisciplinary ideas. This model was used to analyze the leadership of President Recep Tayyip Erdoğan and Angela Merkel through selected case studies. Also, an important contribution of this model is that other scholars can analyze various research questions with different approaches, behaviors and reflections. Consequently, the SNA Leadership Model can be modified for different research questions, is dynamic and flexible similar to the nature of leadership.

\section{References}

Ahmed, N., (2011). The international relations of crisis and the crisis of international relations: from the securitisation of scarcity to the militarisation of society. Global Change, Peace \& Security, 23(3), 335-355.

Allport, G. W. and Vernon, P. E. (1931). A study of values. Boston: Houghton Mifflin.

Aspect, A., Dalibard, J. and Roger, G. (1982). Experimental Test of Bell's Inequalities Using Time- Varying Analyzers. Physical Review Letters, 49(25), 1804-1807.

Bachmann, S. (2012). Hybrid threats, cyber warfare and NATO's comprehensive approach for countering 21st century threats - mapping the new frontier of global risk and security management. Amicus Curiae, 2011(88).

Bhattacherjee, A. (2012). Social science research: Principles, methods, and practices. Createspace Independent Publications

Bailer-Jones, D. (2009). Scientific models in philosophy of science. Pittsburgh, Pa.: University of Pittsburgh Press.

Bauman, Z. and Haugaard, M. (2008). Liquid modernity and power: A dialogue with Zygmunt Bauman1. Journal of Power, 1(2), 111-130. 
Bennett, R. (2016). The kaleidoscope called leadership. Industrial and Commercial Training, 48(2): 86-88.

Berthoz, A. (2012). Simplexity: Simplifying Principles for a Complex World (An Editions Odile Jacob Book). Yale University Press.

Beyer, A. (2018). Peace in International Relations. Peace Review, 30(1), 87-94.

Braithwaite, R. (1953). Scientific explanation. A study of the function of theory, probability and law in science. Based upon the Tarner lectures, 1946. Cambridge.

Breuning, M. (2007). Introduction to comparative foreign policy analysis. Basingstoke: Palgrave Macmillan.

Byman, D. L. and Pollack, K. M. (2001). Let us now praise great men: Bringing the statesman back in. International security, 25(4), 107-146.

Checkland, P. (1981), Systems Thinking. Systems Practice, Wiley, London.

Chowdhury, R. (2019). Systems thinking for management consultants: Introducing holistic flexibility. Springer Singapore.

Coll, R.K. and Lajium, D. (2011). Modeling and the future of science learning. In: Khine M., Saleh I. (eds) Models and Modeling. Models and Modeling in Science Education. Springer, Dordrecht, 3-21

Dekleva, K. B. (2018). Leadership Analysis and Political Psychology in the 21st Century. The journal of the American Academy of Psychiatry and the Law, 46(3), 359363.

Dobson, A. and Marsh, S. (2013). Anglo-American relations. London: Routledge.

Edwards, J. (2001). Multidimensional Constructs in Organizational Behavior Research: An Integrative Analytical Framework. Organizational Research Methods, 4(2), 144-192.

Elbe, S. and Buckland-Merrett, G. (2019). Entangled security: Science, co-production, and intra-active insecurity. European Journal of International Security, 4(2), 123-141.

Erçetin, Ş. Ş. (2016). Understanding Recep Tayyip Erdoğan and Turkey with plasma as a metaphor of the fourth state of matter. In In: Erçetin Ş. eds. Chaos, Complexity and Leadership 2014. Springer Proceedings in Complexity. Springer, Springer, Cham., 113

Erçetin, Ş. Ş. and Açıkalın, Ş.N. (2016). Is President Erdoğan Really a Dictator?: The Illusion of the Opposition Parties in Turkey. In in Ş. Ş. Erçetin and $\mathrm{H}$. Bagci eds. Handbook of Research on Chaos and Complexity Theory in the Social Sciences. IGI Global, 1-18

Farrell, M. (2013). Leadership Mistakes. Journal of Library Administration, 53(7-8), 439450.

Flexner, S. (1987). The Random House dictionary of the English language. 2nd ed. New York: Random House.

Galtung, J. (1996). Peace by peaceful means: Peace and conflict, development and civilization. International Peace Research Institute Oslo; Sage Publications, Inc 
Gelb, M. J. (2017). The Art of Connection: 7 Relationship-building Skills Every Leader Needs Now. New World Library.

Geyer, R., \& Rihani, S. (2010). Complexity and public policy: A new approach to twentyfirst century politics, policy and society. Routledge.

Giere, R. (2004). How Models Are Used to Represent Reality. Philosophy of Science, 71(5), 742-752.

Gribbin, J. (2004). Deep simplicity: Chaos, complexity and the emergence of life. New York: Penguin UK.

Hall, T. and Yarhi-Milo, K. (2012). The Personal Touch: Leaders' Impressions, Costly Signaling, and Assessments of Sincerity in International Affairs. International Studies Quarterly, 56(3), 560-573.

Hamza, K. and Mellouli, S. (2018). Background on frameworks for policy analytics. In: Gil-Garcia J., Pardo T., Luna-Reyes L. eds. Policy Analytics, Modelling, and Informatics. Public Administration and Information Technology. Springer, Cham., 1937

Harper, S. C. (2006). Extraordinary entrepreneurship: The professional's guide to starting an exceptional enterprise. John Wiley \& Sons

Harris, G. (2009). The art of quantum planning. San Francisco: Berrett-Koehler Publishers.

Hinnebusch, R. and Hinnebusch, R. (2008). The International Politics of the Middle East. Oxford: Manchester University Press.

Höfler, M. (2005). The Bradford Hill considerations on causality: a counterfactual perspective. Emerging themes in epidemiology, 2(1), 1-9.

Hutten, E.H. (1953). The role of models in physics. The British Journal for the Philosophy of Science, 4(16), 284-301.

Jervis, R. (1997). Complexity and the Analysis of Political and Social Life. Political Science Quarterly, 112(4), 569.

Jönsson, C. (1990). Handbook of International RelationsPinter. In W.Carlsnes, T.Risse, B.E. S,immons(Eds). Communication in international bargaining ( $\mathrm{pp}$ 212-235).SAGE Publications

Karns, M., Mingst, K. and Stiles, K. (2010). International organizations. Boulder, Col.: Lynne Rienner Publ.

Kesselring, S. (2008). The Mobile Risk Society. In: Canzler, W., Kaufmann, V., \& Kesselring, S. eds. Tracing mobilities: Towards a cosmopolitan perspective. Ashgate Publishing, Ltd.

Kluger, J. (2008). Simplexity. New York: Hyperion.

Klein, P. G., Mahoney, J.T., McGahan, A.M. and Pitelis, C.N. (2010). Toward a theory of public entrepreneurship. European management review, $7(1), 1-15$.

Lassiter, C., 2019. Language and simplexity: A powers view. Language Sciences, 71, 2737. 
Law, K., Wong, C. and Mobley, W. (1998). Toward a Taxonomy of Multidimensional Constructs. The Academy of Management Review, 23(4), 741.

Little, D. (1993). On the scope and limits of generalizations in the social sciences. Synthese, 97(2), 183-207.

Mastenbroek, W. (1999) 'Negotiating as Emotion Management', Theory, Culture \& Society, 16(4), 49-73.

Mäki, U. (2009). MISSing the World. Models as Isolations and Credible Surrogate Systems. Erkenntnis, 70(1), 29-43.

Morrison, M. and Morgan, M. (2000). Models as Autonomous Agents. In: M. Morgan and M. Morrison, ed., Models as Mediators: Perspectives on Natural and Social Science. Cambridge: Cambridge University Press, 38-65.

Nuswantoro, A. (2010). Political Leadership and Foreign Policy: Study of Soekarno's Confrontation Policy Against Malaysia. SSRN Electronic Journal.

Obschonka, M. and Fisch, C. (2018). Entrepreneurial personalities in political leadership. Small Business Economics, 50(4), 851-869.

Olson, C. and Singer, P. (2004). Winning with library leadership. Chicago: American Library Association.

Petrini, C. M. (1991). Upside-down performance appraisals. Training \& Development, 45(7), 15-22.

Petzinger, T. (1999). Complexity-More Than a Fad?. In Lissack, M.R and Gunz H.P, eds, Managing Complexity in Organizations, A View in Many Directions, Westport, CT: Quorum Books

Post, J. (1979). Personality profiles in support of the Camp David Summit. Studies in Intelligence, 23, 1-5.

Post, J. (2014). Personality profiling analysis. In: R. Rhodes and P. Hart, ed., The Oxford Handbook of Political Leadership. London: Oxford University Press, 328-346.

Praszkier, R. and Nowak, A. (2011). Social entrepreneurship: Theory and practice. Cambridge University Press.

Raines, L. (2013). Coaching and Leading as Stewards for Sustainability. In On Becoming a Leadership Coach (pp. 229-242). Palgrave Macmillan, New York.

Ramadas, J. (2009). Visual and spatial modes in science learning. International Journal of Science Education, 31(3), 301-318.

Renshon, J. and Renshon, S. A. (2008). The theory and practice of foreign policy decision making. Political Psychology, 29(4), 509-536.

Robertson, R. (1992). Globalization: Social theory and global culture (Vol. 16). Sage.

Robertson, D. (2002). A dictionary of modern politics. Europa Publications.

Rokeach, M. (1973). The nature of human values. New York: Macmillan.

Rubin, J.Z. (2002). The actors in negotiation. International negotiation: Analysis, approaches, issues, pp.97-109. 
Schneider, M. and Teske, P. (1992). Toward a theory of the political entrepreneur: evidence from local government. The American Political Science Review, 737-747.

Schumpeter, J.A. (1942). Socialism, capitalism and democracy. Harper and Brothers.

Stückelberger, C. (2016). Global Ethics Applied: Global Ethics, Economic Ethics (Vol. 1). Globethics. net.

Tulloch, S. (1992). The Oxford dictionary of new words: a popular guide to words in the news. Oxford University Press, USA.

Tomé, L. and Açıkalın, Ş.N. (2017). Complexity theory as a new Lens in IR: System and change. In in S. Ş Erçetin and N. Potas .Eds. Chaos, Complexity and Leadership 2017 Explorations of Chaos and Complexity Theory. Springer: pp. 1-15.

Toon, A. (2016). Imagination in scientific modeling. In: A. Kind, ed., The Routledge Handbook of Philosophy of Imagination. Routledge.

Ülgül, M. (2019). Erdoğan's Personal Diplomacy and Turkish Foreign Policy. Insight Turkey, 21(4), pp.161-182.

Weick, A. (1991). The place of science in social work. J. Soc. \& Soc. Welfare, 18, 13.

Winsberg, E. (2001). Simulations, models, and theories: Complex physical systems and their representations. Philosophy of Science, 68(S3), 442-454.

Zohar, I. (2015). "The Art of Negotiation" Leadership Skills Required for Negotiation in Time of Crisis. Procedia-Social and Behavioral Sciences, 209, 540-548. 